\title{
The association of serum gamma-glutamyl transpeptidase level and other laboratory parameters with blood pressure in hypertensive patients under ambulatory blood pressure monitoring
}

\author{
Adile Ortakoyluoglu \\ Betul Boz \\ Oguzhan Sıtkı Dizdar \\ Deniz Avcl \\ Ali Cetinkaya \\ Osman Baspınar
}

Department of Internal Medicine, Kayseri Training and Research Hospital, Kayseri, Turkey
Correspondence: Oguzhan Sıtkı Dizdar Department of Internal Medicine and Clinical Nutrition, Kayseri Training and Research Hospital, 78 Hastance Street, Atatürk Avenue, Kocasinan Kayseri 380I0, Turkey

Tel +903523368884

Fax +903523368857

Email osdizdar@gmail.com
This article was published in the following Dove Press journal:

Therapeutics and Clinical Risk Management

7 September 2016

Number of times this article has been viewed

Background: Hypertension is a very important cause of morbidity and mortality. Serum gamma-glutamyl transpeptidase (GGT) is a biomarker of oxidative stress and associated with increased risk of hypertension and diabetes. The aim of this study was to evaluate the association of serum GGT level, which is an early marker of inflammation and endothelial dysfunction, with the deterioration of the diurnal rhythm of the blood pressure.

Methods: A total of 171 patients with hypertension were included in this study. Patients whose nighttime mean blood pressure, measured via ambulatory blood pressure monitoring, decreased between $10 \%$ and $20 \%$ compared with the daytime mean blood pressure were defined as "dippers", whereas patients with a nighttime blood pressure decrease lower than $10 \%$ were defined as "non-dippers".

Results: A total of 99 hypertensive patients ( 65 females/34 males) were classified as dippers and 72 patients (48 females/24 males) as non-dippers. The mean age of the non-dipper group was significantly greater than the dipper group. Serum GGT, C-reactive protein and uric acid levels were significantly higher among patients in the non-dipper group. Negative correlations were detected between GGT levels and diurnal systolic and diastolic blood pressure decreases.

Conclusion: Our findings revealed that GGT level was higher in the non-dipper group, and was negatively correlated with the nighttime decrease of diurnal blood pressure. C-reactive protein and uric acid levels were also higher in the non-dipper group. However, future randomized controlled prospective studies with larger patient populations are necessary to confirm our findings.

Keywords: gamma-glutamyl transpeptidase, hypertension, ambulatory blood pressure monitoring, laboratory parameters

\section{Introduction}

Hypertension is a very important cause of morbidity and mortality because of the end-organ damages it is associated with. ${ }^{1}$ Blood pressure measurements obtained via ambulatory blood pressure monitoring (ABPM) are more accurate than those measured in the outpatient clinics in predicting end-organ damage and cardiovascular events. ${ }^{2,3}$ Mean blood pressure values when sleeping through the night are $10 \%-20 \%$ lower than the activity period during the day. Patients whose blood pressures decrease $<10 \%$ are defined as "non-dipper" hypertensives (no blood pressure drop at night), whereas 
patients with a decrease $>10 \%$ are classified as "dipper" hypertensives (blood pressure drop at night). End-organ damage is found to be more severe among non-dipper hypertensives compared to dipper hypertensive patients, and it is recognized as a risk factor for increased mortality rate..$^{2-4}$

Gamma-glutamyl transpeptidase (GGT) is located at the outer surface of the cells in various tissues such as liver, kidneys, and pancreas. Glutathione biosynthesis, which is the major thiol antioxidant, by way of the gamma-glutamyl cycle is important for maintaining glutathione homeostasis and normal redox status. GGT plays key roles in glutathione homeostasis by breaking down extracellular glutathione and providing cysteine, the rate-limiting substrate, for intracellular de novo synthesis of glutathione. GGT increases the amount of reactive oxygen species in the presence of iron ions and facilitates glutathione-dependent low-density lipoprotein oxidation. ${ }^{5,6}$ GGT activity predicts morbidity and mortality, independent from alcohol consumption and liver disease. ${ }^{7,8}$ There are several studies in the literature, which consistently show that serum GGT level is a biomarker of oxidative stress and is associated with increased risk of hypertension and diabetes. ${ }^{5,9}$

The aim of this study was to evaluate the association between serum GGT level, which is an early marker of inflammation and endothelial dysfunction, with the deterioration of the diurnal rhythm of the blood pressure.

\section{Materials and methods}

A total of 171 patients with hypertension who were followed up at the Nephrology and Hypertension Outpatient Clinic of Kayseri Training and Research Hospital between March 2012 and August 2012 were included in this study. This study was approved by the Ethics Committee of Erciyes University Medical School, and written informed consent forms in accordance with the Declaration of Helsinki were obtained from all the patients who had volunteered to be included in the study. Age, height, weight, and telephone number of the patients were recorded from the medical files retrospectively, along with their current antihypertensive medications, smoking habits, comorbidities, and serum biochemical markers. Body mass (Quetelet) index (BMI) was calculated by the equation of "BMI $=$ weight $/$ height ${ }^{2}\left(\mathrm{~kg} / \mathrm{m}^{2}\right)$ ".

ABPM measurements were performed by ambulatory measurement equipment (Delmar Reynolds Medical Pressurometer $^{\circledR}$, Irvine, CA, USA), and blood pressure was monitored every 30 minutes for 24 hours. Patients with a discrepancy $>5 \mathrm{mmHg}$ in blood pressure values measured with the ABPM device and conventional methods were excluded. Patients were trained in how to continue their daily life without using their arms where blood pressure was being measured. The 24-hour blood pressure measurement data were transferred to a software program. Venous blood samples obtained after at least 12 hours of nocturnal fasting were analyzed for biochemical and hormonal biomarkers with enzymatic, calorimetric, and immunoassay methods by Abbott Aeroset Auto-analyzer (Chicago, IL, USA) and Immulite1000 device (Los Angeles, CA, USA) in the Biochemistry Laboratory of the Kayseri Training and Research Hospital.

Patients whose nighttime mean blood pressure measured with ABPM decreased between $10 \%$ and $20 \%$ compared with the daytime mean blood pressure were defined as "dippers", whereas patients with a nighttime blood pressure decrease $<10 \%$ were defined as "non-dippers". In this study, cellular and biochemical markers of inflammation, biochemical parameters such as GGT, and mean daytime and nighttime blood pressure values were compared between dippers and non-dippers.

\section{Statistical analysis}

Data are expressed as mean \pm standard deviation (SD) or noun (percentage). The normality and the homogeneity of the data were evaluated by Shapiro-Wilk test and Levene test, respectively. Comparisons between groups for continuous variables were performed using the Student's $t$-test (normal distribution) or the Mann-Whitney $U$-test (non-normal distribution). Fisher's test or $\chi^{2}$ test was used for all categorical data. Pearson's correlation test was used to assess the association between GGT and daytime and nighttime blood pressure measurements and changes. The correlation was considered to be weak, moderate, strong, and very strong if the $r$ values were $0.00-0.24,0.25-0.49,0.50-0.74$, and $0.75-1$, respectively. Logistic regression analysis was used to determine the relative risks of developing non-dipper hypertension. Only the variables with a statistically significant association in the simple logistic regression model were included in the multiple logistic regression model. Odds ratios and $95 \%$ confidence intervals were determined. All calculations used the SPSS statistical package (version 15.0; SPSS Inc., Chicago, IL, USA). $P<0.05$ was considered statistically significant.

\section{Results}

This study was performed on 171 patients with essential hypertension who were followed at the Nephrology and Hypertension Outpatient Clinic of Kayseri Training and Research Hospital. Of all the patients, 113 were females, and 58 were males. A total of 99 hypertensive patients (65 females/34 males) were classified as dippers and 72 patients (48 females/24 males) as non-dippers. The percentages of female patients in the dipper and non-dipper groups were $66 \%$ 
Table I Demographic and epidemiologic characteristics of the patients

\begin{tabular}{|c|c|c|c|}
\hline Variable & Dipper group $(n=99)$ & Non-dipper group $(n=72)$ & $P$-value \\
\hline Sex (female/male), n (\%) & $65(66) / 34(34)$ & $48(67) / 24(33)$ & 0.890 \\
\hline Age (years), mean \pm SD & $43.8 \pm 13.7$ & $52.3 \pm 14.4$ & 0.0002 \\
\hline BMI $\left(\mathrm{kg} / \mathrm{m}^{2}\right)$, mean $\pm \mathrm{SD}$ & $28.5 \pm 5.1$ & $28.3 \pm 4.1$ & 0.780 \\
\hline Smoking, n (\%) & $32(32)$ & $22(3 \mathrm{I})$ & 0.800 \\
\hline Diabetes mellitus, n (\%) & $13(13)$ & $7(10)$ & 0.490 \\
\hline Coronary artery disease, $\mathrm{n}(\%)$ & $9(9)$ & $8(11)$ & 0.660 \\
\hline Chronic kidney failure, $\mathrm{n}(\%)$ & $4(4)$ & $2(2)$ & 0.800 \\
\hline \multicolumn{4}{|l|}{ Antihypertensive drug usage, $n(\%)$} \\
\hline One drug only & $16(16)$ & $6(8)$ & 0.130 \\
\hline Two drugs & $64(65)$ & $48(67)$ & 0.780 \\
\hline Three or more drugs & $19(19)$ & $18(25)$ & 0.360 \\
\hline
\end{tabular}

Abbreviations: BMI, body mass index; SD, standard deviation.

and $67 \%$, respectively. There was no statistically significant difference in terms of ratio of females to males between the dipper and non-dipper groups $(P=0.89)$. The mean age of the non-dipper group was significantly greater than the dipper group (52.3 \pm 14.4 vs $43.8 \pm 13.7, P=0.0002)$. The mean BMI (28.5 \pm 5.1 vs $28.3 \pm 4.1, P=0.78)$ and ratio of smokers (32/99 vs $22 / 72, P=0.8$ ) were similar in both groups. The dipper and non-dipper groups were not significantly different in terms of the presence of diabetes mellitus, coronary artery disease, and chronic renal failure, which are related to the end-organ damage. Moreover, the number of antihypertensive medications was similar in both groups. The demographic characteristics of the patients are presented in Table 1.

The biochemical parameters of the dipper and non-dipper groups were compared. Serum GGT levels $(36.2 \pm 13.8$ vs $20.5 \pm 8.8 \mathrm{U} / \mathrm{L}, P=0.03$ ) and $\mathrm{C}$-reactive protein (CRP) values $(7.2 \pm 7.1$ vs $3.78 \pm 4.6 \mathrm{mg} / \mathrm{L}, P=0.02)$ were significantly higher among patients in the non-dipper group. Similarly, uric acid levels were greater in the non-dipper group $(6.3 \pm 1.6$ vs $5.14 \pm 2.1 \mathrm{mg} / \mathrm{dL}, P=0.01)$. Other laboratory parameters were similar between the two groups.
The biochemical parameters of the patients are shown in Table 2. Furthermore, we divided patients into two groups according to mean blood pressure: group 1 (lower blood pressure group) consisted of patients whose mean blood pressures were $<135 / 85 \mathrm{mmHg}$; group 2 (higher blood pressure group) consisted of patients whose mean blood pressures were higher than $135 / 85 \mathrm{mmHg}$ (Table 3). Only creatinine value was significantly higher in the higher blood pressure group.

The mean decreases in the systolic blood pressure (diurnal variation) in the dipper and non-dipper groups were $12.6 \pm 4.3 \mathrm{mmHg}$ and $4.3 \pm 4.5 \mathrm{mmHg}$, respectively $(P<0.01)$. The mean decrease in diurnal diastolic blood pressure was $15.1 \pm 4.2 \mathrm{mmHg}$ and $5 \pm 4.8 \mathrm{mmHg}$ in the dipper and nondipper groups, respectively $(P<0.01)$. The ABPM results of the groups are demonstrated in Table 4.

The correlation coefficients between the laboratory and ABPM findings are presented in Table 5. There were no significant correlations between GGT levels and nighttime systolic and diastolic blood pressures $(P=0.200$ and $P=0.230)$. However, negative correlations were detected

Table 2 Comparison of the biochemical parameters of the patients

\begin{tabular}{|c|c|c|c|}
\hline \multirow[t]{2}{*}{ Blood biochemistry } & \multirow{2}{*}{$\frac{\text { Dipper group }(\mathrm{n}=99)}{\text { Mean } \pm \text { SD }}$} & \multirow{2}{*}{$\frac{\text { Non-dipper group }(n=72)}{\text { Mean } \pm \text { SD }}$} & \multirow[t]{2}{*}{$P$-value } \\
\hline & & & \\
\hline GGT, U/L & $20.5 \pm 8.8$ & $36.2 \pm 13.8$ & 0.030 \\
\hline Creatinine, $\mathrm{mg} / \mathrm{dL}$ & $0.74 \pm 0.22$ & $0.8 \pm 0.3$ & 0.220 \\
\hline $\mathrm{ALT}, \mathrm{U} / \mathrm{L}$ & $24.7 \pm 18.9$ & $22.4 \pm 12.8$ & 0.370 \\
\hline Total cholesterol, mg/dL & $196.1 \pm 50.7$ & $197.1 \pm 53.4$ & 0.900 \\
\hline LDL-cholesterol, mg/dL & $112.6 \pm 36.4$ & $116.6 \pm 36.4$ & 0.540 \\
\hline HDL-cholesterol, mg/dL & $51.9 \pm 13.1$ & $50.6 \pm 15.3$ & 0.610 \\
\hline Triglyceride, mg/dL & $157.8 \pm 38.1$ & $153.9 \pm 40.2$ & 0.730 \\
\hline Albumin, $g / d L$ & $4.37 \pm 0.99$ & $4.36 \pm 0.3$ & 0.530 \\
\hline CRP, mg/L & $3.78 \pm 4.6$ & $7.2 \pm 7.1$ & 0.020 \\
\hline Uric acid, mg/dL & $5.14 \pm 2.1$ & $6.3 \pm 1.6$ & 0.010 \\
\hline
\end{tabular}

Abbreviations: ALT, alanine aminotransferase; CRP, C-reactive protein; GGT, gamma-glutamyl transpeptidase; HDL, high-density lipoprotein; LDL, low-density lipoprotein; $\mathrm{SD}$, standard deviation. 
Table 3 Comparison of the laboratory parameters according to mean blood pressure level

\begin{tabular}{|c|c|c|c|}
\hline \multirow[t]{2}{*}{ Blood biochemistry } & \multirow{2}{*}{$\begin{array}{l}\text { Lower blood pressure } \\
\text { group }(n=104) \\
\text { Median (range) }\end{array}$} & \multirow{2}{*}{$\begin{array}{l}\text { Higher blood pressure } \\
\text { group }(n=67) \\
\text { Median (range) }\end{array}$} & \multirow[t]{2}{*}{$P$-value } \\
\hline & & & \\
\hline GGT, U/L & $67.5(24-306)$ & $65(44-384)$ & 0.429 \\
\hline Creatinine, mg/dL & $0.7(0.5-2)$ & $0.8(0.5-3)$ & 0.015 \\
\hline $\mathrm{ALT}, \mathrm{U} / \mathrm{L}$ & $18.5(5-174)$ & $22.5(10-74)$ & 0.270 \\
\hline Total cholesterol, mg/dL & $195.5(90-319)$ & $196.5(\mid 13-290)$ & 0.562 \\
\hline LDL-cholesterol, mg/dL & $115(35-211)$ & $120(39-190)$ & 0.430 \\
\hline HDL-cholesterol, mg/dL & $47.5(31-94)$ & $46(53-101)$ & 0.269 \\
\hline Triglyceride, mg/dL & $147(80-436)$ & $161(42-526)$ & 0.351 \\
\hline Albumin, $g / d L$ & $4.6(I .1-5.2)$ & $4.4(0.5-4.9)$ & 0.178 \\
\hline $\mathrm{CRP}, \mathrm{mg} / \mathrm{L}$ & $3(2-14)$ & $3(2-147)$ & 0.086 \\
\hline Uric acid, mg/dL & $5(3-11)$ & $6(I-12)$ & 0.140 \\
\hline
\end{tabular}

Abbreviations: ALT, alanine aminotransferase; CRP, C-reactive protein; GGT, gamma-glutamyl transpeptidase; HDL, high-density lipoprotein; LDL, low-density lipoprotein.

between GGT levels and diurnal systolic and diastolic blood pressure decreases $(r=-0.153, P=0.04$ and $r=-0.16, P=0.03$, respectively). There were positive correlations between CRP levels and both nighttime systolic and diastolic blood pressures ( $r=0.15, P=0.04$ and $r=0.15, P=0.04$, respectively). Negative correlations were found between diurnal systolic and diastolic blood pressure decreases and CRP levels $(r=-0.18, P=0.02$ and $P=0.01$, respectively), as well as with uric acid levels ( $r=-0.23, P=0.001$ and $r=-0.21, P=0.001$, respectively).

Logistic regression analysis was used to determine the relative risks of developing non-dipper hypertension. Only the variables with a statistically significant association in the simple logistic regression model were included in the multiple logistic regression model. In the multiple logistic regression analysis, there was no significant risk factor associated with non-dipper hypertension (Table 6).

\section{Discussion}

Blood pressure measurement plays an important role in the diagnosis and management of hypertension. National Institute

Table 4 Comparison of ambulatory blood pressure monitoring results of the groups

\begin{tabular}{|c|c|c|c|}
\hline \multirow{2}{*}{$\begin{array}{l}\text { Ambulatory blood } \\
\text { pressure }(\mathrm{mmHg})\end{array}$} & \multirow{2}{*}{$\frac{\text { Dipper group }}{\text { Mean } \pm \text { SD }}$} & \multirow{2}{*}{$\frac{\text { Non-dipper group }}{\text { Mean } \pm \text { SD }}$} & \multirow[t]{2}{*}{$P$-value } \\
\hline & & & \\
\hline SBP, daytime & $131.3 \pm 18.8$ & $128.8 \pm 17.4$ & 0.370 \\
\hline SBP, nighttime & $116.1 \pm 15.3$ & $125 \pm 19.5$ & 0.001 \\
\hline SBP, mean & $\mid 27.1 \pm 17.0$ & $127.5 \pm 17.0$ & 0.880 \\
\hline DBP, daytime & $82.9 \pm 12.6$ & $80.2 \pm I I . I$ & 0.140 \\
\hline DBP, nighttime & $70.8 \pm 10.7$ & $76.9 \pm 13.3$ & 0.001 \\
\hline DBP, mean & $79.4 \pm 11.6$ & $79.3 \pm 11.2$ & 0.950 \\
\hline SBP, decrease & $12.6 \pm 4.3$ & $4.3 \pm 4.5$ & 0.0001 \\
\hline DBP, decrease & $15.1 \pm 4.2$ & $5 \pm 4.8$ & 0.0001 \\
\hline
\end{tabular}

Abbreviations: DBP, diastolic blood pressure; SBP, systolic blood pressure; $\mathrm{SD}$, standard deviation. for Health and Care Excellence (UK) 2011 guidelines recommend ABPM to confirm the diagnosis of hypertension if clinical blood pressure is $\geq 140 / 90 \mathrm{mmHg} .{ }^{10}$ If the patient cannot tolerate ABPM, blood pressure measurements may be repeated at home to confirm the diagnosis of hypertension. Patients with daytime blood pressure values $\geq 135 / 85 \mathrm{mmHg}$ according to ABPM or home blood pressure measurements are diagnosed as hypertensive. ${ }^{10} \mathrm{ABPM}$ enables the assessment of the changes in the circadian blood pressure pattern for 24 hours during routine activities. Moreover, ABPM prevents the phenomenon of "white coat hypertension", as it measures the blood pressure outside the health center. Furthermore, ABPM demonstrates the true prevalence of hypertension and evaluates the end-organ involvement in patients with hypertension. The Canadian Hypertension Education Program 2012 guidelines strongly recommend ABPM to confirm the clinical blood pressure measurements. ${ }^{11}$

Hill initially showed that nocturnal decrease in blood pressure is a characteristic property of diurnal blood pressure changes. ${ }^{12}$ Impairment in sleep quality, increased sympathetic system activity, and decreased parasympathetic system activity are responsible for the occurrence of non-dipper blood pressure phenomenon. Several studies demonstrated that non-dipper patients had increased morbidity and mortality. Moreover, non-dipper hypertension is considered a risk factor for the development of diabetes. Therefore, nondipper blood pressure may also be regarded as a risk factor for cardiovascular diseases and end-organ damage. These findings suggest that non-dipper patients must be closely monitored for the development of cardiovascular diseases and they must be treated aggressively. In a study performed by Galindo et al, it has been demonstrated that non-dipper prevalence is increased especially among patients older than 65 years of age, and this finding was linked to impaired sleep 
Table 5 The correlation analysis between the laboratory and ambulatory blood pressure monitoring findings

\begin{tabular}{|c|c|c|c|c|c|c|c|c|}
\hline \multirow[t]{2}{*}{ Variable } & \multicolumn{2}{|c|}{ SBP, nighttime } & \multicolumn{2}{|c|}{ DBP, nighttime } & \multicolumn{2}{|c|}{$\begin{array}{l}\text { SBP, diurnal } \\
\text { decrease }\end{array}$} & \multicolumn{2}{|c|}{$\begin{array}{l}\text { DBP, diurnal } \\
\text { decrease }\end{array}$} \\
\hline & $r$ & $P$-value & $r$ & $P$-value & $\boldsymbol{r}$ & $P$-value & $r$ & $P$-value \\
\hline GGT, U/L & 0.09 & 0.200 & 0.08 & 0.230 & -0.153 & 0.040 & -0.16 & 0.030 \\
\hline CRP, mg/L & 0.125 & 0.040 & 0.15 & 0.040 & -0.18 & 0.020 & -0.17 & 0.010 \\
\hline Uric acid, mg/dL & 0.15 & 0.100 & 0.09 & 0.200 & -0.23 & 0.001 & -0.21 & 0.001 \\
\hline
\end{tabular}

Abbreviations: CRP, C-reactive protein; DBP, diastolic blood pressure; GGT, gamma-glutamyl transpeptidase; $r$, correlation coefficient; SBP, systolic blood pressure.

quality and presence of comorbidities. ${ }^{13}$ Similarly, the prevalence of hypertension and end-organ damage risk increases with the increase in age.

GGT is a systolic enzyme, which is generally synthesized in tissues such as liver, kidney, prostate and brain, and responsible for the intracellular oxidation/reduction events, and plays a role in the glutathione cycle. In their eleven-year-long study, Wannamethee et al demonstrated that elevated GGT activities are associated with increased mortality. ${ }^{7}$ This association was considered to be linked to the increased cardiovascular deaths due to ischemic heart disease underlined by insulin resistance in patients with elevated GGT levels. ${ }^{7}$ In the population-based, multi-center CARDIA study aiming to determine the coronary artery disease risk in young adults, researchers found that elevated GGT levels were associated with the development of diabetes and hypertension. The authors recorded that oxidative stress may play a role in the increased risk of diabetes and hypertension. ${ }^{14}$ It has been concluded that GGT is an early-acting and sensitive enzyme, which is associated with oxidative stress. In this study, we detected that association between serum GGT level and non-dipper/dipper blood pressure phenomenon, which is considered as a prognostic marker of cardiovascular health. Our patients whose mean blood pressures were $>135 / 85$ $\mathrm{mmHg}$ did not have significantly higher GGT levels, but had significantly higher creatinine value. This situation can be related with the effects of uncontrolled hypertension to renal function.

In a prospective study performed by Verdecchia et al on 1,392 patients, the authors could not find any significant

Table 6 Results of multiple logistic regression analysis for risk factors for non-dipper hypertension

\begin{tabular}{llll}
\hline Risk factors & OR & $\mathbf{9 5 \%} \mathbf{C l}$ & $P$-value \\
\hline Age & 1.02 & $0.989-1.047$ & 0.222 \\
CRP & 1.09 & $0.953-1.248$ & 0.210 \\
Uric acid & 0.97 & $0.791-1.193$ & 0.782 \\
GGT & 1.01 & $0.996-1.017$ & 0.240 \\
\hline
\end{tabular}

Abbreviations: $\mathrm{Cl}$, confidence interval; CRP, C-reactive protein; GGT, gammaglutamyl transpeptidase; OR, odds ratio. difference in total cholesterol levels between non-dipper and dipper hypertensive patients, but they detected that serum triglyceride levels were significantly higher in the non-dipper group. ${ }^{2}$ In the present study, however, we could not find any significant difference between the lipid profiles of the patients in the two groups. Moreover, we could not detect significant differences in the other laboratory findings of the patients, except GGT, CRP, and uric acid levels. Serum GGT, CRP, and uric acid levels were significantly higher in the nondipper group compared with the dipper group. These findings are in accordance with those of Ermis et al where the authors also found that GGT and CRP levels were significantly higher among the non-dipper hypertensive patients compared with the dipper hypertensive patients ( $P=0.02$ and $P=0.046$, respectively). ${ }^{15}$ Although Ermis et al's study had smaller sample size of hypertensive patients than ours, 46 healthy subjects were additionally included in their study. Serum GGT and CRP levels were higher in the non-dipper and the dipper groups than in the control group (healthy subjects). All of these findings together with our results may explain that increased GGT and CRP levels may be one of the reasons behind the non-dipper hypertension-related cardiovascular complications.

Several studies have demonstrated that serum uric acid levels play an important prognostic role, especially in the progression of hypertension and coronary artery disease. . $^{16,17}$ Yamamoto et al reported an association between hyperuricemia and hypertension, and suggested that the treatment of resistant hypertensive patients should be tailored considering their uric acid levels. The authors recorded that $1 \mathrm{mg} / \mathrm{dL}$ increase in the uric acid levels corresponded to $20 \mathrm{mg} / \mathrm{dL}$ change in cholesterol level in terms of cardiovascular disease risk. ${ }^{17}$

Broad epidemiological studies have demonstrated that CRP level is an independent risk factor for the development of cardiovascular diseases. These observations suggested that inflammation may have a role in the pathogenesis of hypertension. The insufficient nighttime decrease in blood pressure may result in increased endothelial damage and vascular inflammation due to increased pressure exposure 
of the endothelium. This may cause elevated CRP and uric acid levels in the non-dipper group. In accordance with other studies in the literature, we found increased inflammatory markers in patients who showed non-dipper blood pressure pattern in ABPM.

ABPM cannot be applied to every hypertensive patient in daily clinical practice. Therefore, some parameters are required to identify non-dipper patients. GGT, CRP, and uric acid are parameters that have been frequently measured in daily clinical practice, and in our study their levels were found to be significantly higher in non-dipper patients. Therefore, we think that these parameters may have prognostic significance in hypertensive patients, but in our multiple logistic regression analysis, there was no significant risk factor associated with non-dipper hypertension. Therefore, this issue requires further investigation.

Angiotensin II type I receptor blockers, angiotensinconverting enzyme inhibitors, and calcium channel blockers are well-established antihypertensive drugs that are frequently used as first-line drugs for treating hypertension. Nishida et al evaluated and compared the effects of different antihypertensive drugs on laboratory parameters. ${ }^{18}$ There was no significant difference in GGT levels between different drug groups in this study. Similarly, we did not find any relationship between drugs and laboratory parameters. Antihypertensive drugs may make some changes in laboratory parameters, but multiple factors may be contributing to these changes.

A major limitation of our study is the smaller sample size compared to other studies. Further and larger clinical and experimental studies are required to understand the role of GGT on the diagnosis and evaluation of hypertension. Not having a control group may be another limitation of this study. Although there were no statistically significant differences in the number of the antihypertensive medications between the two groups, these medications may affect the diurnal blood pressure profile and biochemical parameters. Therefore, these type of medications may have an impact on the statistical results of our study.

\section{Conclusion}

In this study, we evaluated the association between serum GGT level, which is accepted as a novel biochemical biomarker of oxidative stress, and blood pressure in hypertensive patients who underwent ABPM. Our findings revealed that GGT level was higher in the non-dipper group and was negatively correlated with the diurnal nighttime blood pressure decrease. CRP and uric acid levels, both of which are associated with oxidative stress and inflammation, were also higher in the non-dipper group. However, future randomized controlled prospective studies with larger patient populations are necessary to confirm our findings.

\section{Author contributions}

$\mathrm{AO}$ and $\mathrm{BB}$ contributed to the study concept and design, analysis and interpretation of the data, statistical analysis, and manuscript writing; OSD contributed to the study concept and design, gave professional advice on statistical analysis and interpretation of the data, and manuscript preparation; $\mathrm{OB}, \mathrm{DA}$ and AC performed the research and collected data. All authors contributed toward data analysis, drafting and revising the paper and agree to be accountable for all aspects of the work. All authors reviewed and approved the final manuscript.

\section{Disclosure}

The authors report no conflicts of interest in this work.

\section{References}

1. Carretero OA, Oparil S. Essential hypertension. Part I: definition and etiology. Circulation. 2000;101:329-335.

2. Verdecchia P, Porcellati C, Schillaci G, et al. Ambulatory blood pressure: an independent predictor of prognosis in essential hypertension. Hypertension. 1994;24(6):793-801.

3. Perloff D, Sokolow M, Cowan R. The prognostic value of ambulatory blood pressure monitoring in treated hypertensive patients. J Hypertens Suppl. 1991;9(1):33-39.

4. Mancia G, Zanchetti A, Agebeti-Rosie E, et al. Ambulatory blood pressure is superior to clinic blood pressure in predicting treatment-induced regression of left ventricular hypertrophy. SAMPLE study group. Study on ambulatory monitoring of blood pressure and lisinopril evaluation. Circulation. 1997;95(6):1464-1470.

5. Nilssen O, Forde OH, Brenn T. The Tromso study. Distribution and population determinants of gamma-glutamyl transferase. Am J Epidemiol. 1990;132(2):318-326.

6. Shankar A, Li J. Association between Serum Gamma-Glutamyl transferase level and prehypertension among US adults. Circ J. 2007; 71(10):1567-1572.

7. Wannamethee G, Ebrahim S, Shaper AG. Gamma-glutamyl transferase: determinants and association with mortality from ischemic heart disease and all causes. Am J Epidemiol. 1995;142(7):699-708.

8. Ruttmann E, Brant LJ, Concin H, Diem G, Rapp K, Ulmer H; Vorarlberg Health Monitoring and Promotion Program Study Group. Gamma-glutamyl transferase as a risk factor for cardiovascular disease mortality: an epidemiological investigation in a cohort of 163,944 Austrian adults. Circulation. 2005;112(14):2130-2137.

9. Lee DH, Blomhoff R, Jacobs DR Jr. Is serum gamma glutamyl transferase a marker of oxidative stress? Free Radic Res. 2004;38(6): 535-539.

10. National Institute for Health and Clinical Excellence. Hypertension: clinical management of primary hypertension in adults. (Clinical guideline 127.) 2011. http://www.nice.org.uk/CG127. Accessed January 12, 2013.

11. Rabi DM, Daskalopoulou SS, Padwal RS, et al; Canadian Hypertension Education Program. The 2011 Canadian hypertension education program recommendations for the management of hypertension: blood pressure measurement, diagnosis, assessment of risk, and therapy. Can J Cardiol. 2011;27(4):415-433. 
12. Hill L. On rest, sleep, and work and the concomitant changes in the circulation of the blood. Lancet. 1898;151:282-285.

13. Galindo C, Soler A, Meritxell S, et al. To be non-dipper: a higher cardiovascular risk? Am J Hypertens. 2004;17(5):205A.

14. Lee DH, Jacobs DR Jr, Gross M, et al. Gamma glutamyl transferase is a predictor of incident diabetes and hypertension: the coronary artery risk development in young adults (CARDIA) Study. Clin Chem. 2003; 49(8):1358-1366.

15. Ermis N, Yagmur J, Acikgoz N, et al. Serum gamma-glutamyl transferase (GGT) levels and inflammatory activity in patients with nondipper hypertension. Clin Exp Hypertens. 2012;34(5):311-315.
16. Ebrahimpour P, Fakhrzadeh H, Heshmat R, Bandarian F, Larijani B. Serum uric acid levels and risk of metabolic syndrome in healthy adults. Endocr Pract. 2008;14(3):298-304.

17. Yamamoto Y, Matsubara K, Igawa G, et al. Status of uric acid management in hypertensive subjects. Hypertens Res. 2007;30(6):549-554.

18. Nishida Y, Takahashi Y, Nakayama T, Asai S. Comparative effect of angiotensin II type I receptor blockers and calcium channel blockers on laboratory parameters in hypertensive patients with type 2 diabetes. Cardiovasc Diabetol. 2012;11:53.

\section{Publish your work in this journal}

Therapeutics and Clinical Risk Management is an international, peerreviewed journal of clinical therapeutics and risk management, focusing on concise rapid reporting of clinical studies in all therapeutic areas, outcomes, safety, and programs for the effective, safe, and sustained use of medicines. This journal is indexed on PubMed Central, CAS,
EMBase, Scopus and the Elsevier Bibliographic databases. The manuscript management system is completely online and includes a very quick and fair peer-review system, which is all easy to use. Visit http://www.dovepress.com/testimonials.php to read real quotes from published authors.

Submit your manuscript here: http://www.dovepress.com/therapeutics-and-clinical-risk-management-journal 